\title{
DO FEMALE YELLOW-BELLIED MARMOTS ADJUST THE SEX RATIOS OF THEIR OFFSPRING?
}

\author{
Kenneth B. Armitage \\ Division of Biological Sciences, University of Kansas, Lawrence, Kansas 66045 \\ Submitted March 3, 1986; Accepted August 25, 1986
}

Current evolutionary theory predicts that vertebrates maintaining large outcrossed populations should invest equally in sons and daughters when sons and daughters are equally costly at all stages of parental investment (Williams 1979). The argument was first advanced by Fisher (1930) and is based on the premise that the minority sex has a mating advantage. Thus, a sex bias favoring females makes males more valuable, and selection favors the increased production of males. As the proportion of males increases, they become less valuable. At equilibrium, neither sex has an advantage, and the population sex ratio is one to one (Maynard Smith 1984). However, if reproductive success varies more widely among the offspring of one sex and is influenced by parental investment (Trivers 1972), parents should invest more heavily in that sex either by investing more per individual (Reiter et al. 1978) or by producing more individuals of the preferred sex (Trivers and Willard 1973).

Several theories discuss conditions under which individual females should produce more individuals of one sex, that is, bias the sex ratio of their offspring (reviewed in Williams 1979). Although most of the evidence supporting adaptive variations in sex ratios of mammals is inconclusive (see review in Clutton-Brock and Albon 1982), evidence has accumulated that demonstrates consistent and significant deviations from 1:1 sex ratios in some species of mammals (CluttonBrock 1985). Most species of mammals are secretive; therefore, patterns of investment are virtually impossible to determine in natural populations. Consequently, it is necessary to test the theory of sex-ratio adjustment indirectly by testing predictions derived from the theory. Furthermore, the observed trends in sex ratios of mammals do not clearly support any particular adaptive theory (Clutton-Brock 1985). The purpose of this paper is threefold: (1) to present evidence of sex-ratio adjustment in the polygynous yellow-bellied marmot (Marmota flaviventris); (2) to test the applicability of current theories to marmots; and (3) to present a general theory that sex-ratio adjustment in mammals is biased toward the sex that has the higher probability of future reproductive success. 


\section{THEORY}

Testing theories of sex-ratio adjustment requires careful consideration of their assumptions. The fundamental premise is that variation in female condition leads to differential investment in sons and daughters (Trivers and Willard 1973; Clark 1978). Clark's model stems from the observation that the predominance of male dispersal and female philopatry in mammals could lead to local resource competition (LRC) among resident females (Smith 1968; Clark 1978). The model of Trivers and Willard and the LRC model make different predictions about the proximal causes and direction of sex-ratio biases. Trivers and Willard assumed that adult females in the best condition produce the healthiest offspring and that differences in condition affect the reproductive success of males more strongly than that of females. Under these assumptions, an adult female in good condition that produces a son leaves more surviving grandchildren than a similar female that produces a daughter. By contrast, a female in poor condition that produces a daughter leaves more surviving grandchildren than a similar female that produces a son. Species with an especially high variance in male reproductive success compared with female reproductive success should, as a function of differences in maternal condition, exhibit an especially high variance in sex ratios. It follows from this argument that sex-ratio adjustment should be more likely in strongly polygynous species, especially those species with marked sexual dimorphism. The sex-ratio bias should be expressed in a sex-ratio variance among the progeny greater than the binomial (Williams 1979).

Several predictions are possible from the hypothesis of Trivers and Willard. In most natural mammalian populations, female condition declines with increased age (Sadleir 1969). Therefore, offspring of older females should be predominantly female. Females producing large litters invest more energy totally but less per offspring than females producing small litters (Millar 1978, 1979). Therefore, small litters should contain more males. Socially stressed females may be unable to obtain food or to allocate energy efficiently to pregnancy or lactation. Therefore, stressed females (in poor condition) should produce female-biased litters. It follows that if stressed females also produce smaller litters, small litters should be female-biased. The sex bias of small litters depends on female condition (Trivers and Willard 1973; McGinley 1984).

The LRC model predicts that high-ranking females (in good condition) should produce more daughters than sons because daughters could inherit their mother's social rank and its associated preferential access to resources. By contrast, lowerranking females (in poor condition) should produce sons that will disperse and have opportunities for reproductive success elsewhere (Clark 1978; Altmann 1980; Silk 1983).

Resource competition should be inversely related to the number of adult females. The LRC model predicts an increase in male births at higher densities because fewer daughters will be able to inherit their mother's resources. By contrast, the model of Trivers and Willard predicts an increase in daughters because adult females should be in poorer condition because of competition and 
should produce the sex whose reproductive success is less affected by maternal condition.

Both models are attempts to explain adaptive sex ratios in terms of the proximate factors inducing biased sex ratios. I propose that numerous factors can cause sex-ratio bias in offspring, but that the direction of the bias depends on which sex's future reproductive success can be affected by the mother. In other words, it is the consequences of the sex bias, not the cause, on which natural selection acts.

\section{STUDY ANIMALS AND METHODS}

The social behavior and population dynamics of the semi-fossorial yellowbellied marmot have been studied in the East River Valley, Gunnison County, Colorado, since 1962. Each year, all animals in the study sites are trapped and marked with distinctive patterns of fur dye for visual identification. At that time, their reproductive condition and body weight are recorded. When an animal is first captured, a numbered ear tag is inserted in each ear for permanent identification.

Marmots breed annually (Armitage and Downhower 1974); young usually emerge from their natal burrows in July at three to four weeks of age (Armitage et al. 1976). At this time, young are readily trapped, sexed, and tagged. Because only rarely do two or more breeding females occupy the same burrow (Armitage 1984), young may be assigned to a particular female. Thus, the sex ratio at weaning of individual litters may be associated with adult females of known age and social status. Most theoretical discussions and evidence for sex-ratio modification emphasize birth sex ratios (Clutton-Brock and Albon 1982). The critical sex ratio for a female mammal is, however, the ratio at weaning; sex ratios may be altered by differential female investment during lactation (McClure 1981). Sex ratios at weaning could be affected by infanticide; however, infanticide among marmots is rare (Armitage 1979; Brody and Melcher 1985).

At weaning, the population sex ratio (males/females) does not differ significantly from 1.0 (Armitage and Downhower 1974). Among adults 3 yr old or older, the sex ratio is 0.71 , a value significantly different from $1.0\left(\chi^{2}=5.7,0.025>P>\right.$ 0.01 ). Because females are clumped and several can be defended by one male, the breeding sex ratio averages 0.33 (Armitage 1986a). Males are larger than females at all ages (Armitage et al. 1976); on the average, adult males weigh 1.3 times as much as adult females (Armitage 1981). Adult and breeding sex ratios suggest that variance in reproductive success is greater for males than for females. Furthermore, sexual dimorphism at weaning indicates that females invest more in individual sons than in individual daughters. Because there is a fixed cost for synthesizing biomass (Calow 1977), the larger males are a consequence of greater energy intake and, hence, of greater maternal investment.

Yellow-bellied marmots become reproductive when $2 \mathrm{yr}$ old. Young hibernate in their natal area. Virtually all yearling males emigrate; 53\% of the yearling females remain within their natal populations. The recruitment of daughters into their natal population produces matrilines of closely related females (Armitage 
1984). An adult male forms a harem by defending the females in one or more matrilines. Matrilines vary from one to five adult females; the mean size is 1.45. The mean length of residence of a matriline is $4.35 \mathrm{yr}$; matrilines either become extinct or divide into daughter matrilines (Armitage 1984, 1986a). Mortality, coupled with failure to recruit daughters and division into daughter matrilines, frequently produces a matriline (a genealogy) of one female that may live for several years as the only member of a matriline. Matrilineal formation increases the probability that a female can produce one or more reproductively successful daughters, but she cannot directly affect the reproductive success of her emigrant sons. Presumably, a female can increase the probability of reproductive success of her male offspring by producing either more males or higher-quality males. We have no evidence that females act to produce higher-quality sons; therefore, we postulate that females may produce more sons. Females who are unlikely to recruit daughters should produce more sons than daughters.

The age of adult females, litter size, sex of weaned young, and social structure were determined from recorded demographic data and field observations. The number of adult females was measured in three ways: number per matriline, number per harem, and number per habitat patch. Four categories of social structure were established: females living alone, females living in a matriline with no other adult females present, females living singly with another matriline present, and females living in a matriline with another matriline present. Because the age of adult females was not always known, the number of litters varies among the analyses.

The effect of stress on annual reproductive output was measured for $2 \mathrm{yr}$ in two ways. First, animals were tested by mirror-image stimulation (MIS; Svendsen and Armitage 1973; Svendsen 1974). The behavioral data were analyzed by factor analysis. A total of 59 adult and yearling marmots formed the data set; 21 were adult females of varying ages. Reproductive output was available for 14 females, 10 of which provided data for $2 \mathrm{yr}$.

Second, a blood sample was taken from each animal (Armitage 1983), and the eosinophil concentration was measured. Blood was diluted using the Unopettesystem $^{\circledR}$ technique (Becton-Dickinson, N.J.). Eosinophils were counted in a hemacytometer. The eosinophils appeared as red granular cells; other leukocytes were unstained, and erythrocytes were hemolyzed. Because samples were taken throughout the summer over a 2-yr period, multiple samples were obtained from most individuals and were averaged. Eosinophil concentrations were available for 52 of the 59 animals used for MIS. Because some females were present in both years, 56 litters could have been produced. However, only 18 litters were weaned.

Social status was determined from MIS factor scores for 19 adult females for whom lifetime reproductive output was available. Three social groups corresponding to the three major MIS axes were formed. Each female was assigned to a group according to the axis on which she had her highest factor score. Group-II females, the subordinate females, represent a particularly stable group; repeated MIS testing over several years revealed that these females do not change their social status (Svendsen 1974). Lifetime reproductive output was obtained for each of the 19 females. 
TABLE 1

The Relationship between Litter Size and Sex Ratio in Yellow-Bellied Marmots

\begin{tabular}{|c|c|c|c|c|c|c|}
\hline \multirow{2}{*}{$\begin{array}{c}\text { Population } \\
\text { Characteristic }\end{array}$} & \multicolumn{6}{|c|}{ LitTer Size (mEAN, 3.97) } \\
\hline & 1 & 2 & 3 & 4 & 5 & $\geq 6$ \\
\hline No. of litters & 10 & 10 & 41 & 39 & 32 & 24 \\
\hline No. of males & 6 & 14 & 64 & 72 & 74 & 74 \\
\hline No. of females & 4 & 6 & 59 & 84 & 86 & 76 \\
\hline Proportion of males & 0.6 & 0.7 & 0.52 & 0.46 & 0.46 & 0.49 \\
\hline \multicolumn{7}{|l|}{ Sex ratio } \\
\hline$\chi^{2}$ & 0.4 & 3.2 & 2.0 & 0.9 & 0.9 & 0.03 \\
\hline$\stackrel{?}{P}$ & 0.5 & $0.1-0.05$ & $>0.5$ & $>0.1$ & $>0.1$ & $>0.5$ \\
\hline \multicolumn{7}{|l|}{ Binomial distribution } \\
\hline$x^{2}$ & & 3.6 & 2.4 & 8.5 & 7.2 & 2.2 \\
\hline$P$ & & $>0.1$ & 0.5 & $0.1-0.05$ & $>0.1$ & $>0.9$ \\
\hline
\end{tabular}

$G$-test or $\chi^{2}$ analysis and binomial distribution were performed (according to procedures in Sokal and Rohlf 1969).

\section{RESULTS}

\section{Litter Size}

The overall sex ratio of 619 young from 156 litters did not differ significantly from $1.0\left(\chi^{2}=0.19, P>0.5\right)$. Although the sex ratio did not differ significantly from 1.0 for any size of litter (table 1), small litters tended to be male-biased and large litters to be female-biased. Therefore, all litters below mean size were combined, as were all litters above mean size. The sex ratio of each group did not differ significantly from 1.0 (below mean size, $\chi^{2}=1.5, P>0.1$; above mean size, $\left.\chi^{2}=1.5, P>0.1\right)$. Although the overall sex ratio did not differ significantly from 1.0 , the production of males could be nonrandom within litters. Randomness in sex determination should produce litters ranging from no males to all males for litters of all sizes, with frequencies following a binomial distribution. Deviations from the binomial distribution might not be statistically detected by $\chi^{2}$ analysis of the overall sex ratio, but they could be biologically significant. Therefore, the expected distribution of the number of males per litter based on the binomial distribution was compared with the observed distribution for all litters of two or larger. The observed distribution of males did not differ from the expected distribution at any litter size (table 1). I conclude that there is no evidence of sexratio adjustment associated with litter size.

\section{Age of Female}

The overall sex ratio of 446 young in 114 litters from females of known age did not differ significantly from $1.0\left(\chi^{2}=2.6,0.5>P>0.1\right)$. However, the sex ratio of young produced by 3 -yr-old females was significantly female-biased (table 2 ), and the excess of daughters produced by 2 -yr-old females approached significance. These results suggested a general trend for young females to produce 
TABLE 2

The Relationship between Age of the Adult Female and Sex Ratio in Yellow-Bellied Marmots

\begin{tabular}{|c|c|c|c|c|c|}
\hline \multirow[b]{2}{*}{ AGE* } & \multirow{2}{*}{$\begin{array}{l}\text { No. of } \\
\text { LitTERS }\end{array}$} & \multirow{2}{*}{$\begin{array}{l}\text { No. of } \\
\text { MaLES }\end{array}$} & \multirow{2}{*}{$\begin{array}{l}\text { No. of } \\
\text { FEMALES }\end{array}$} & \multicolumn{2}{|c|}{ Sex Ratio } \\
\hline & & & & $x^{2}$ & $P$ \\
\hline 2 & 22 & 35 & 52 & 3.3 & $0.1-0.05$ \\
\hline 3 & 22 & 32 & 51 & 4.4 & $0.05-0.025$ \\
\hline 4 & 24 & 43 & 51 & 0.7 & $>0.1$ \\
\hline 5 & 14 & 34 & 23 & 2.1 & $>0.1$ \\
\hline 6 & 12 & 27 & 18 & 1.8 & $>0.1$ \\
\hline 7 & 10 & 19 & 22 & 0.2 & $>0.5$ \\
\hline 8 & 6 & 10 & 14 & 0.7 & $>0.1$ \\
\hline$\geq 9$ & 4 & 6 & 9 & 0.6 & $>0.1$ \\
\hline
\end{tabular}

* Mean, 4.4 yr.

female-biased litters. Therefore, all litters were combined into two groups, those from females lower than the mean age (young) and those from females older than the mean age (old) (table 2). Young females produced female-biased litters $\left(\chi^{2}=\right.$ $7.3,0.01>P>0.005)$. Old females did not produce sex-biased litters $\left(\chi^{2}=0.5\right.$, $0.5>P>0.1)$. The distribution of the number of males per litter for litters of 3,4 , and 5 did not differ significantly from a binomial distribution $(P>0.2)$ for old females. However, the distribution of males in litters of 4 and 5 differed significantly from a binomial distribution $(P<0.02)$ for young females. There were few litters containing three or more males; in other words, larger litters had more females than expected.

\section{Number of Resident Females}

The overall ratio of 654 young from 168 litters did not differ significantly from $1.0\left(\chi^{2}=0.15, P>0.5\right)$. The null hypothesis that the sex ratio of weaned young is independent of the size of the group of females to which the mother belongs was rejected for matrilines $(G=9.27$, df $=4,0.06>P>0.05)$ and accepted for harems $(G=9.45$, df $=5,0.1>P>0.05)$ and for total number per habitat (i.e., colony; may be more than one harem; $G=4.45, \mathrm{df}=6, P>0.5$ ). The sex ratio of each population group was tested by $\chi^{2}$ analysis to determine which groups had a sex ratio significantly different from that of the overall population (table 3). Matrilines of two adult females produced more daughters than sons. Although other trends are evident, none is statistically significant.

\section{Stress}

Factor analysis of the MIS behavioral data produced three factors accounting for $85 \%$ of the variance (Svendsen 1974). Factor I was represented by marmots that spent most of their time in the front half of the arena oriented to their images. This group contained aggressive and socially dominant animals. Factor II was designated "avoidance" because animals remained in the rear of the arena and usually did not approach the mirror or did so hesitantly. Factor III was characterized by animals that engaged in nose contact, pawing and muzzling of the image, 
TABLE 3

The Relationship between the Number of Resident Adult Females and Sex Ratio in Yellow-Bellied Marmots

\begin{tabular}{|c|c|c|c|c|c|}
\hline \multirow{3}{*}{$\begin{array}{l}\text { Number of } \\
\text { Adult } \\
\text { FEMALES }\end{array}$} & & \multicolumn{4}{|c|}{ Population Group } \\
\hline & & \multicolumn{2}{|c|}{ Matriline } & Harem & Habitat \\
\hline & & $\mathbf{M}$ & $\mathrm{F}$ & $\mathrm{M}$ & M F \\
\hline 1 & $P$ & $\stackrel{167}{>0.1}$ & 152 & $\begin{array}{cr}80 & 62 \\
0.05-0.1\end{array}$ & ${ }^{70}>0.15$ \\
\hline 2 & $P$ & $\begin{array}{l}62 \\
<0.025\end{array}$ & $25^{95}$ & ${ }^{86}>0.1111$ & ${ }^{57}>0.5^{63}$ \\
\hline 3 & $P$ & $\stackrel{48}{>0.1}$ & 42 & ${ }^{54}>0.5^{51}$ & 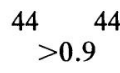 \\
\hline 4 & $P$ & $\stackrel{37}{>0.1}$ & 31 & ${ }^{62}>0.1^{56}$ & ${ }^{57}>0.5^{56}$ \\
\hline 5 & $P$ & $\begin{array}{l}8 \\
>0.1\end{array}$ & 12 & $\begin{array}{cc}26 & 41 \\
0.05-0.1\end{array}$ & ${ }^{48}>0.1^{64}$ \\
\hline 6 & $P$ & & & ${ }^{14}>0.1^{11}$ & ${ }^{33}>0.9^{35}$ \\
\hline 7 & $P$ & & & & ${ }^{13}>0.5^{15}$ \\
\hline
\end{tabular}

NotE.-The numbers are the observed numbers of males and females in each population group. The $P$ values are for $\chi^{2}$ tests for significant differences. Expected numbers of males and females were calculated from the population means: males $(\mathrm{M}), 0.492$; females $(\mathrm{F}), 0.508$.

and exploring the arena. These animals were categorized as "sociable." Field observations of avoidance animals revealed that they were generally subordinate in their social encounters and tended to avoid associating with other adults (Svendsen and Armitage 1973; Svendsen 1974). Animals in this group, those scoring high on the factor-II axis, seemed the most likely candidates to experience social stress.

Eosinophil numbers decrease in subordinate animals; eosinopenia indicates stress (Vandenbergh 1960). Eosinophil concentration and MIS may not be independent measures of stress. Therefore, factor scores for each animal were ranked from high to low for each of the three factors. Eosinophil concentrations also were ranked from high to low. The relationships between the two rankings were tested by the Kendall partial-rank correlation (Siegel 1956, p. 223). Eosinophil concentrations were negatively correlated with the avoidance factor (partial $Y=$ $-0.234)$. Although there is no test of significance for the Kendall partial-rank correlation, probability was estimated by calculating $z$ in the same manner as for the rank correlation (Siegel 1956, p. 221). Estimated $P$ was 0.0003. Animals that scored highest on avoidance had low eosinophil concentrations. However, the amount of variation explained by the avoidance-eosinophil correlation is low, as evidenced by the low correlation coefficient. Therefore, each measure was treated separately as an index of stress.

The effects of stress as measured by MIS were tested by dividing the animals into two groups, those whose factor scores were above the median on axis II 
(stressed, $n=7$ ) and those whose scores were below the median (unstressed, $n=$ 7). Sex ratios did not differ significantly from $1.0\left(\chi^{2}<0.72, P>0.1\right)$. However, stress affected litter production. On the average, half of the adult females reproduce in any year (Armitage 1986a). Unstressed females were four times more likely to produce a litter than not $\left(\chi^{2}=5.4, P<0.025\right)$, whereas the proportion of stressed females that reproduced did not differ from the expected $0.5\left(\chi^{2}=0.1, P\right.$ $>0.5$ ).

The effects of stress as measured by eosinophil concentration were tested by dividing the animals into two groups. One group consisted of animals whose eosinophil concentration was above the median (unstressed, $n=11$ ); the other group contained those whose eosinophil concentration was below the median (stressed, $n=7)$. Sex ratios did not differ significantly from $1.0\left(\chi^{2}<0.05, P>\right.$ $0.5)$. Stressed females had a one-third probability of reproducing $\left(\chi^{2}=6.2, P<\right.$ $0.025)$, whereas unstressed females produced litters at the predicted rate $\left(\chi^{2}=\right.$ $0.9, P>0.1)$. I conclude that stress does not affect sex ratios but that it does affect the likelihood of weaning a litter.

\section{Social Structure}

Each female occurred in one of four social environments: (1) living alone; (2) living in a matriline of two or more adult females; (3) living singly adjacent to another matriline; (4) living in a matriline of two or more adult females with another matriline present. There was no evidence for sex-ratio adjustment. Only one $\chi^{2}$ exceeded 1.0; all $P$ 's were $>0.1$.

Because social structure and age of females could interact, young (below mean age) and old (above mean age) females were placed in one of the four social groups. Young females living in a matrilineal group produced significantly more daughters than sons (table 4). The high $\chi^{2}$ value and low probability in comparison with the other values in table 4 suggest that this relationship is not a statistical accident but represents an underlying biological reality.

Young females lived in three different social groupings: mother-daughter, sister-sister, and sister-sister-daughter (of one of the sisters). Of the 26 matrilines with only one matriline present, 12 were mother-daughter, 12 were sister-sister, and 2 were sister-sister-daughter. Of the 9 cases with more than one matriline present, 5 were mother-daughter and 4 were sister-sister. Among old females, 24 of 26 matrilines were mother-daughter, one was sister-sister, and one was sistersister-daughter. All mother-daughter and sister-sister matrilines had an average relatedness of 0.5 . Thus, relatedness cannot explain the female sex bias in the offspring of young adult females living in a matriline when no other females were present. The overwhelming preponderance of mother-daughter matrilines among old females is a consequence of demography (it is unlikely that two sisters would live to be $5 \mathrm{yr}$ old or older) or the subdivision of matrilines (old sisters are likely to separate and form their own matrilines).

\section{Social Status}

The sex ratio of weaned young produced over a female's lifetime differed significantly among females in the three MIS groups (table 5). Females in the 
TABLE 4

The Relationship between the Sex Ratio of Weaned Young, Recruitment, and the Age of Female Adult Marmots Living under Different Social Conditions

\begin{tabular}{|c|c|c|c|c|}
\hline \multirow{4}{*}{$\begin{array}{l}\text { Population } \\
\text { Characteristic }\end{array}$} & \multicolumn{2}{|c|}{$\begin{array}{l}\text { OnLy MatriLine } \\
\text { PRESENT }\end{array}$} & \multicolumn{2}{|c|}{$\begin{array}{c}\text { Other MATRILINe } \\
\text { PrESENT }\end{array}$} \\
\hline & Only & Other & Only & Other \\
\hline & Female & Female(s) & Female & Female(s) \\
\hline & Present & Present & Present & Present \\
\hline & \multicolumn{4}{|c|}{ BELOW MEAN AGE (YOUNG) } \\
\hline \multicolumn{5}{|l|}{ Sex ratio } \\
\hline No. of litters & 17 & 25 & 17 & 10 \\
\hline Males & 32 & 37 & 24 & 18 \\
\hline Females & 37 & 67 & 32 & 20 \\
\hline$x^{2}$ & 0.4 & 8.7 & 1.1 & 0.1 \\
\hline$\hat{P}$ & $>0.5$ & $<0.005$ & $>0.1$ & $>0.5$ \\
\hline \multicolumn{5}{|l|}{ Recruitment* } \\
\hline No. of litters & 15 & 20 & 10 & 5 \\
\hline \multicolumn{5}{|l|}{ Females } \\
\hline Recruited & 15 & 27 & 6 & 2 \\
\hline Disappeared & 21 & 30 & 14 & 10 \\
\hline Recruits/litter & 1.0 & 1.4 & 0.6 & 0.4 \\
\hline$x^{2}$ & 1.4 & 11.4 & 0.7 & 1.4 \\
\hline$\widehat{P}$ & $>0.1$ & $<0.001$ & $>0.1$ & $>0.1$ \\
\hline Recruits/ $q$ young, $\bar{X}$ & 0.42 & 0.47 & 0.30 & 0.17 \\
\hline$x^{2}$ & 1.0 & 4.5 & 0.1 & 1.6 \\
\hline \multirow[t]{2}{*}{$\stackrel{x}{P}$} & $>0.1$ & $<0.05$ & $>0.5$ & $>0.9$ \\
\hline & \multicolumn{4}{|c|}{ ABOVE MEAN AGE (OLD) } \\
\hline \multicolumn{5}{|l|}{ Sex ratio } \\
\hline No. of litters & 19 & 6 & 14 & 5 \\
\hline Males & 47 & 12 & 28 & 9 \\
\hline Females & 34 & 14 & 24 & 11 \\
\hline$x^{2}$ & 2.1 & 0.08 & 0.3 & 0.2 \\
\hline$\stackrel{\hat{P}}{P}$ & $>0.1$ & $>0.5$ & $>0.5$ & $>0.5$ \\
\hline \multicolumn{5}{|l|}{ Recruitment* } \\
\hline No. of litters & 15 & 5 & 8 & 4 \\
\hline \multicolumn{5}{|l|}{ Females } \\
\hline Recruited & 3 & 5 & 2 & 4 \\
\hline Disappeared & 25 & 9 & 10 & 7 \\
\hline Recruits/litter & 0.2 & 1.0 & 0.25 & 1.0 \\
\hline$x^{2}$ & 11.1 & 0.4 & 6.0 & 0.3 \\
\hline$\hat{P}$ & $<0.001$ & $>0.5$ & $<0.025$ & $>0.5$ \\
\hline Recruits/ $q$ young, $\bar{X}$ & 0.11 & 0.36 & 0.17 & 0.36 \\
\hline$x^{2}+y=10$ & 6.7 & 0.1 & 1.6 & 0.4 \\
\hline$\hat{P}$ & $<0.01$ & $>0.1$ & $>0.1$ & $>0.5$ \\
\hline
\end{tabular}

* The sample size is smaller for recruitment analysis because recruitment data were not available for all litters.

avoidance group produced more males than expected; the sex ratios of the young in the other groups did not differ significantly from 1.0. However, there was no significant difference in litter size $\left(F_{2,38}=0.68, P>0.5\right)$ or in the number of young produced per female over her lifetime $\left(F_{2,16}=0.5, P>0.5\right)$ among the three groups of females. 


\section{TABLE 5}

Lifetime Production of Weaned Young, Residence Time, and Recruitment Summed by MiS Group for Female Yellow-Bellied Marmots

\begin{tabular}{lccc}
\hline \hline & \multicolumn{3}{c}{ MIS GrouP* } \\
\cline { 2 - 4 } Population Characteristic & I (11) & II (4) & III (4) \\
\hline No. of weaned young & 38 & 20 & 16 \\
Male & 32 & 7 & 24 \\
Female & 31 & 23 & 20 \\
Total no. of years of residence & 6 & 2 & 6 \\
No. of recruitment events &
\end{tabular}

* The number of females in each group for mirror-image stimulation is given in parentheses. Sex ratios differ significantly among the groups $\left(\chi^{2}=7.68, P<0.025\right)$.

\section{DISCUSSION}

\section{An Adaptive Explanation for Sex-Ratio Adjustment by Marmots}

The most striking conclusion from this study is that biased sex ratios are associated with social organization rather than with predictions based on parentalallocation models. Thus, the older females in the sample did not produce femalebiased litters, small litters were not sex-biased, and stressed females did not produce sex-biased litters. Females in small groups (in good condition) did not produce male-biased sex ratios, and females in large groups (in poor condition) did not bias sex ratios in favor of daughters.

The LRC model cannot account for the marmot results. Resource competition (for foraging areas and burrows) should occur when marmots occur in large groups; therefore, marmots living singly should produce daughters, and marmots living in large groups should produce sons. Male-biased litters did not occur. There were no density effects in larger social groups - harems or habitat-where competition should be most intense, especially among matrilines. Matrilines compete with one another, and reproductive inhibition may occur (Armitage 1986a). Furthermore, there was no sex-ratio bias in larger matrilines, where competition among members of a matriline should be most intense (table 3). When sex-ratio bias did occur, it was in a direction opposite to that predicted by LRC. Finally, LRC does not explain why neither harems of two nor a total of two females in a habitat patch failed to produce female-biased sex ratios, whereas two females living together in a matriline did (table 3 ).

The production of more daughters by young females living in matrilineal groups suggests that the social system of the yellow-bellied marmot is essential to the interpretation of biased sex ratios. Two-thirds of the matrilines of two or more females have only two females (Armitage 1986a). Thus, most of the time when young females live together in the only matriline, the matriline consists of two females. Therefore, the production of female-biased sex ratios by females living in matrilines of two (table 3 ) and of young females living in a matriline of two or more females (table 4) represents the same population. Females living in matrilineal 
groups cooperate to defend resources and to exclude unrelated females (Armitage 1984, 1986a). When other matrilineal groups are absent, daughters may occupy the available space. Thus, a female may enhance her individual fitness by increasing the probability of producing daughters that will survive and reproduce. $\mathrm{Re}$ cruitment of daughters (retaining yearling daughters in the natal area) is twice as likely when the mother is present, but it occurs only half the time when the mother is absent (Armitage 1984). Life-table statistics reveal that adult females aged two through four have greater life expectancies than older females (Armitage and Downhower 1974).

Therefore, I predict that a young female has a higher probability of surviving and recruiting one or more daughters through post-weaning reproductive investment than does an older female. This investment is expressed behaviorally; cohesive behaviors between adult females and their yearling daughters occur more frequently than would be expected by chance encounter (Armitage and Johns 1982). Yearling females are philopatric (Armitage 1975, 1984); food and burrow resources are shared among a mother and her daughters. By contrast, because an older female may not survive another year, she cannot increase her fitness by post-weaning behavioral investment. In her absence, her yearling daughter is likely to emigrate.

If the preceding argument is correct, young females associating in a matrilineal group should recruit more daughters than females living in other social situations or than older females, regardless of their social environment. The null hypothesis that the recruitment of female yearlings is independent of the age-social class distribution was rejected $(G=15.2$, df $=7,0.05>P>0.02)$. Of the total of 190 female young from 82 litters, 64 became recruits. The mean number of recruits was 0.78 per litter. This value was used to calculate an expected number of recruits for each age-social class group by multiplying 0.78 times the number of litters in that group. The expected number of recruits was subtracted from the total number of female young to produce the expected number disappearing (mortality plus emigration; referred to hereafter as "disappeared"). The relationship between the expected and the observed numbers of recruits and disappeared was tested for each age-social class group by $\chi^{2}$ analysis.

When the social group consisted of young females living in the only matriline with other females present, the observed number of recruits was greater than expected (table 4). This result is consistent with the higher proportion of females per litter for this group. Females above the mean age who were the only members of a matriline recruited significantly fewer daughters than expected. Lower recruitment is consistent with the probability of lower survival of old females and their inability to continue post-weaning investment into the second summer of a daughter's life.

The number of recruits per female young weaned averaged 0.34 . This value was used to calculate an expected number of recruits for each age-social class group by multiplying 0.34 times the number of female young in that group. The expected number of recruits was subtracted from the total number to produce the expected number disappearing. Young females living in the only matriline with other females present recruited significantly more daughters than expected (table 4), 
suggesting that recruitment was enhanced by the social environment in which the females lived. Old females living alone retained fewer recruits per daughter than expected. This result is consistent with the expectation that old females are less likely to return the next year; hence, there is no social environment conducive to the yearling daughter's recruitment.

The above analysis suggests that females that recruit daughters should produce female-biased litters. The analysis of lifetime recruitment for the three behavioral phenotypes (table 5) revealed that group-III females recruited significantly more daughters than members of the other groups (Armitage 1986b). Although the sociable group-III females produced more daughters than sons, the difference was not statistically significant. Successful recruiters occurred in all MIS groups. Therefore, the sex ratio of weaned young of all recruiters was compared with that of all non-recruiters. The sex ratio was 1.08 males per female for recruiters and 1.7 for non-recruiters; this difference was not significant $\left(\chi^{2}=1.1, P>0.2\right)$, but it was in the expected direction. Recruitment involves more than sex-ratio adjustment. Sex-ratio adjustment may be a function of the probability of recruitment rather than the eventual occurrence of recruitment.

The production of more sons by subordinate females (table 5) is also related to recruitment. The number of recruitment events (retention of one or more daughters from the same litter) varied considerably in relation to the number of years adult females were resident. The average length of residence for an adult female is $3.26 \mathrm{yr}$ (Armitage 1986a). This value is close to the value for number of years of residence per recruitment event (3.3) for group-III females and far less than the number of years of residence per recruitment event (11.5) for group-II females (table 5). Recruitment is not impossible for a subordinate (group-II) female, but it is highly unlikely. Therefore, these females should invest more in the sex of their offspring that has the higher probability of producing reproductive offspring. Because resident, territorial males are replaced on average every $2.24 \mathrm{yr}$ (Armitage 1986a), a dispersing male may have a higher probability of obtaining residence and reproducing than a dispersing female. Resident, colonial females are likely to be living with or replaced by members of a matriline rather than by an immigrant (Armitage 1984). Thus, female dispersers encounter greater obstacles in becoming residents; colonial females are resident for longer times than males, and immigrants must either displace a matriline or wait for a matriline to die out.

Although most matrilines become extinct, many more male than female immigrants become resident in marmot colonies (Armitage 1984). Even if male and female immigration rates were identical, a successful male may leave more descendants than a successful daughter because the male may father several litters in one year, whereas a female can produce no more than one litter per year (Downhower and Armitage 1971; Armitage and Downhower 1974; Armitage 1986a).

\section{Sex-Ratio Adjustment: Generality of the Models}

Primate studies provide evidence for both female-biased and male-biased sex ratios. Lower-ranking mothers in the rhesus monkey (Macaca mulatta), whose daughters have a lower probability of successful reproduction, produce more 
males (Simpson and Simpson 1982). Low-ranking bonnet macaque females $(M$. radiata) produce significantly more sons than daughters $\left(\chi^{2}=7.5, P<0.01\right.$; my analysis of data published in Silk 1983), whereas the sex ratio of offspring of highranking females is 1:1 (Silk 1983). Among free-ranging M. mulatta, the proportion of males born in social groups is directly correlated with dominance ranks (Meikle et al. 1984). The sons of higher-ranking females are more likely to join nonnatal groups and accrue tenure and rank than are the sons of lower-ranking females. There are no consistent significant differences in sex ratios at the individual, matrilineal, or populational level of the Cayo Santiago macaque population $(M$. mulatta; Rawlins and Kessler 1986). Rawlins and Kessler, in reviewing the macaque studies, suggested that significant sex-ratio biases in small populations may represent random variables in sex ratios, for example, the extensive demographic contribution of a particular female who may produce only sons or daughters. No consistent pattern of support for either the model of Trivers and Willard or the LRC model was evident.

Van Schaik and van Noordwijk (1983) concluded that social tension in primate societies is associated with higher juvenile female mortality and male-biased sex ratios. In primate societies where social tension is low, sex ratios are significantly biased toward daughters. Because the addition of new females to a socially stressed or food-stressed group is curtailed, dominant females direct aggression toward subordinate females and their female offspring. This aggression reduces both the production and the survival of daughters by subordinate females. This analysis is essentially a form of LRC (Silk 1983); however, van Schaik and van Noordwijk did not consider the biased sex ratios to be adaptive.

Biosocial factors may be the dominant factor affecting sex ratios. Dominart female red deer (Cervus elaphus) produce more sons than daughters (CluttonBrock et al. 1981, 1984; Clutton-Brock 1985). The lifetime reproductive success of sons, but not of daughters, of red deer hinds is related to the mother's social rank. Among white-tailed deer (Odocoileus virginianus), sex ratio is related to nutrition; undernourished does tend to produce a surplus of males; even or femaledominated sex ratios occur among older, well-nourished does (Verme 1983; Pederson and Harper 1984). The does occur in matrilineal groups; males emigrate away from their birth localities. The family group can be perpetuated by producing daughters (Ozoga et al. 1982). Doe fawns or yearlings are unlikely to establish a matriline; these females can increase their probability of leaving reproductive descendants by producing sons. Doe fawns and yearlings produce a preponderance of sons (significant only for fawns; Verme 1983). By contrast, wellnourished, prime-aged does are likely to initiate matrilines; these females produce significantly more daughters than young females and produce significantly fewer sons in large litters than in single litters (Verme 1983). Poor nutrition in does usually reflects overcrowding. Under these conditions, the formation of matrilines is unlikely, and male-biased sex ratios predominate. Furthermore, maternally unsuccessful 2-yr-old does revert to subordinate status, seek their mother's leadership, and exhibit breeding characteristics of yearlings; that is, they produce more male progeny than successful mothers of the same age (Ozoga and Verme 1986). 
Among four species of the marsupial Antechinus, all young males disperse; mothers and daughters are highly philopatric (Cockburn et al. 1985). Primaparous females produce male-biased sex ratios in the presence of previously parous females whose offspring sex ratios were unbiased. This result was interpreted as supporting LRC; daughters of the younger females would be unlikely to compete successfully with daughters of older females (Cockburn et al. 1985). However, the sex ratios of the second litter produced by young females are female-biased. I presume that these females form a philopatric association with their daughters. As in white-tailed deer, females produce daughters when the formation of a matriline is likely but produce sons when a matriline is unlikely. Semelparous females produce more daughters than sons; presumably the daughters inherit their mother's resources. It appears that Antechinus females produce daughters when the mother can enhance the likelihood of their daughter's future reproductive success but otherwise produce sons.

In a critique of the Trivers and Willard hypothesis, Myers (1978) hypothesized that poor environmental conditions should lead to the production of the cheaper sex. Because at birth male white-tailed deer (Hesselton and Hesselton 1982) and mule deer (O. hemionus) (Mackie et al. 1982) weigh about the same as females, males cost about the same to produce as females. Regardless of the costs of producing a son or daughter, nutritional stress is associated with male-biased sex ratios at birth (Verme 1965, 1969; Robinette et al. 1973; Pederson and Harper 1984). Although sex-biased ratios occur in Macaca mulatta (Simpson and Simpson 1982; Meikle et al. 1984), there is no evidence that females invest more in individual sons than in individual daughters (Small and Smith 1984). These results are contrary to the predictions of Myers and indicate that the cost of the offspring is not the major determinant of sex-ratio adjustment.

However, when food-stressed mule deer were provided extra rations, the weights of male fawns increased and the proportion of males remained unchanged, but the number of fawns per doe increased (Robinette et al. 1973). Similarly, two populations of food-stressed grey-tailed voles (Microtus canicaudus) did not produce sex ratios that differed significantly from a population fed ad libitum (Goldenberg 1979), but the females fed ad libitum weighed more and produced more litters, heavier offspring, and more-frequent litters than the foodstressed voles. In both cases, females produced as many young as possible in accord with Myers' argument that females should not lose potential offspring in order to modify the sex ratio.

In conclusion, predictions based on the Trivers and Willard model (and McGinley's modification, 1984) are supported by some but not all primate studies, are supported by some studies on deer but not others, and are not supported by the vole study or by the data on yellow-bellied marmots. The LRC model is supported by some but not all primate studies and by some but not all data on Antechinus, is consistent with deer (Odocoileus) but not with vole or marmot studies, and is not supported by the red deer studies.

\section{A Generalized Model}

The preceding section indicates that the data do not consistently support the Trivers and Willard model (see also Clutton-Brock and Albon 1982), its 
modification by McGinley (1984), or the alternative models proposed by Myers (1978), Clark (1978), and Silk (1983). One problem is that parental investment can take different forms, and there is no common currency for comparing these forms (Knapton 1984). For example, female marmots and red deer may invest more energy in producing a son than a daughter because males are larger than females at weaning. But females may invest more social behavior and resource sharing in daughters who become recruits.

Furthermore, none of the various models is generalizable. For example, the LRC model (Silk 1983) describes the conditions under which it is advantageous for some females to bias the sex ratios of their offspring in a given direction. Similarly, density-dependent enforced sex-ratio change (van Schaik and van Noordwijk 1983) also provides a social mechanism under which biased sex ratios occur. The Trivers and Willard model, as applied to rhesus monkeys (Meikle et al. 1984), describes another set of conditions and the consequent sex ratios. In effect, each model describes the particular set of conditions operating at the time the studies were made, but no model applies to all documented cases of sex-ratio adjustment. As suggested by Meikle et al., these models are really special cases of general sexallocation theory (Charnov 1982). Most studies have implicitly or explicitly been intended to refute or support the model of Trivers and Willard or the LRC model. Attempting to reject or to use one of these models as the adaptive explanation for sex-ratio bias exemplifies misplaced emphasis. I suggest that attention should focus on the outcome, not the proximal cause, of sex-ratio bias. The reproductive success of offspring should form the general model for the adaptive explanation of sex-ratio adjustment (see also Silk 1983). At least three, and possibly more, proximal mechanisms may lead to sex-ratio adjustment in mammals. This variability in proximal mechanisms is understandable only if they produce similar effects, that is, if they increase the probability of reproductive success by producing more of the sex that has a higher probability of reproducing.

Evolutionary success accrues to those individuals that produce reproductive descendants. Because survival is an exercise in probability (White 1978), a female's reproductive investment should include all activities that increase the probability that she will have grandchildren. Thus, the sex ratio should be biased toward the sex that has the highest probability of producing the grandchildren. This bias should occur regardless of the cost of producing an individual daughter or son. In other words, it is not the cost of producing sons or daughters that is the critical factor, but the probable survival and reproduction of sons or daughters that is of paramount importance. Although Trivers and Willard (1973) constructed their model in terms of the reproductive success of the offspring, most of the emphasis has been directed to the proximal factors affecting sex-ratio adjustment, such as female condition and the cost of producing an offspring. More recently, Clutton-Brock and Albon (1982) suggested that the sex in which the parent invests more heavily depends on the effects of that investment on the future reproductive success of the offspring. A similar model was proposed to explain male-biased sex ratios in many cooperatively breeding birds. Because sons help at the nest, more are produced as a consequence of that helping, which in turn increases the number of offspring fledged (Emlen et al. 1986).

This interpretation is consistent with the data from the best-studied species. Sex 
ratios of yellow-bellied marmots are male-biased in those females unlikely to form a matriline and female-biased in those females most likely to recruit their daughters. White-tailed deer mothers that are likely to form matrilines produce more daughters than sons (Verme 1983). Primaparous Antechinus produce more sons in the presence of their mothers (Cockburn et al. 1985). Dominant red deer females (Clutton-Brock et al. 1984) produce more sons; maternal rank affects the breeding success of sons more than that of daughters. Male yellow-bellied marmots and male red deer are more expensive to produce; the patterns of sex-ratio adjustment in these species are not consistent with theories relating to the costs of producing individual offspring. Females produced more of the sex whose probability of future reproductive success was greater or whose future reproductive success could be affected by the female.

\section{Mechanisms of Sex-Ratio Allocation}

Although the reproductive success of descendants seems likely to be the ultimate factor explaining sex-ratio allocation, two levels of proximal mechanisms are involved. The first is the populational and social environment in which females opt to produce more of one sex than the other. I argue above that biosocial factors may be a predominant proximal mechanism inducing bias in sex ratios of offspring. In this sense, resource competition among female kin is a biosocial factor. However, other environmental factors are not precluded as proximal factors. The data to date are equivocal. Sex-ratio differences have been reported, but most do not reach statistical significance (Clutton-Brock and Albon 1982).

The second level of proximate analysis is to determine the physiological mechanisms that produce more of one sex than the other. In white-tailed deer, the percentage of males conceived increases with length of time between the onset of estrus and insemination (Verme and Ozoga 1981). In many organisms, a delay in mating or fertilization is associated with an increase in the proportion of males in the next generation (Werren and Charnov 1978). A connection between biosocial factors and increased sex ratios is easily hypothesized. Socially stressed females may mate later in estrus than dominant females; hence, they produce a higher proportion of males.

Male-biased sex ratios may in some instances be a consequence of other factors and not reflect any underlying biosocial determinant. For example, fetal sex ratios of Florida white-tailed deer were male-biased on hunted sites but female-biased on nonhunted sites. The reduction in males on the hunted sites probably caused many females to breed late in estrus, hence the skewed distribution of males (Richter and Labisky 1985). Because the number of fetuses per doe was higher on the hunted area, biosocial hypotheses would predict more female than male offspring (Verme 1983). Thus, this apparent inconsistency is a consequence of the removal of males and the subsequent presumed mating late in estrus. However, the mechanism does produce the more valuable sex and is consistent with the model of probable future reproductive success.

Delay in mating is unlikely to account for the differential sex ratios of yellowbellied marmots of different ages living in different social environments (table 4). The essential requirement is that variability in the time of mating, in the viability 
of $\mathrm{X}$ - and $\mathrm{Y}$-bearing sperm, or in the physiology of the female reproductive tract, acting singly or in combination, affects the probability of whether a given fertilization produces a male or female zygote. Because physiological variability is essential, biased sex ratios need not be genetically determined. It seems more likely that natural selection maintains the physiological variability that is immediately responsive to the proximal factors causing biased sex ratios. Fortunately, evolutionary ecologists can describe the populational and social environment causing biased sex ratios and determine the likely selection pressures favoring sex-ratio bias without knowing the physiological mechanisms involved.

\section{SUMMARY}

The overall sex ratio of weaned yellow-bellied marmots does not differ significantly from one. Litter size has no effect on the sex ratio of young. Stress, measured by eosinophil concentration and mirror-image stimulation, is not associated with biased sex ratios. Three-year-old females and females living in matrilines of two produce more daughters than expected. Females whose age is below the mean produce female-biased litters. Young females that are members of matrilineal social groups produce significantly more daughters than sons. By contrast, the lifetime sex ratios of young produced by subordinate females is malebiased. These results are contrary to those predicted from the model of Trivers and Willard and the model of local resource competition.

The patterns of sex-ratio variation in marmots, primates, red deer, Antechinus, and white-tailed deer suggest that females produce the sex that has a higher probability of future reproductive success, regardless of the costs of producing individuals of that sex.

\section{ACKNOWLEDGMENTS}

This research was conducted at the Rocky Mountain Biological Laboratory, Colorado, and supported by grants GB-32494, GB-8526, BMS74-21193, DEB780727, and DEB82-21231 from the National Science Foundation. G. E. Svendsen performed the analysis of the mirror-image stimulation. I thank the following for their assistance in the field: G. E. Svendsen, Keith Armitage, D. Johns, D. L. Kilgore, Jr., and O. A. Schwartz.

\section{LITERATURE CITED}

Altmann, J. 1980. Baboon mothers and infants. Harvard University Press, Cambridge, Mass.

Armitage, K. B. 1975. Social behavior and population dynamics of marmots. Oikos 26:341-354. 1979. Cannibalism among yellow-bellied marmots. J. Mammal. 60:205-207.

1981. Sociality as a life history tactic of ground squirrels. Oecologia (Berl.) 48:36-49.

1983. Hematological values for free-ranging yellow-bellied marmots. Comp. Biochem. Physiol. A, Comp. Physiol. 74:89-93.

1984. Recruitment in yellow-bellied marmot populations: kinship, philopatry, and individual variability. Pages 377-403 in J. O. Murie and G. R. Michener, eds. The biology of grounddwelling squirrels. University of Nebraska Press, Lincoln.

1986a. Marmot polygyny revisited: determinants of male and female reproductive strategies. 
Pages 303-331 in D. I. Rubenstein and R. W. Wrangham, eds. Ecology of social evolution: field studies of birds and mammals. Princeton University Press, Princeton, N.J.

$1986 b$. Individuality, social behavior, and reproductive success in yellow-bellied marmots. Ecology 67:1186-1193.

Armitage, K. B., and J. F. Downhower. 1974. Demography of yellow-bellied marmot populations. Ecology 55:1233-1245.

Armitage, K. B., and D. Johns. 1982. Kinship, reproductive strategies and social dynamics of yellowbellied marmots. Behav. Ecol. Sociobiol. 11:55-63.

Armitage, K. B., J. F. Downhower, and G. E. Svendsen. 1976. Seasonal changes in weights of marmots. Am. Midl. Nat. 96:36-51.

Brody, A. K., and J. Melcher. 1985. Infanticide in yellow-bellied marmots. Anim. Behav. 33:673-674.

Calow, P. 1977. Conversion efficiencies in heterotrophic organisms. Biol. Rev. Camb. Philos. Soc. 52:385-409.

Charnov, E. L. 1982. The theory of sex allocation. Princeton University Press, Princeton, N.J.

Clark, A. B. 1978. Sex ratio and local resource competition in a prosimian primate. Science (Wash., D.C.) 201:163-165.

Clutton-Brock, T. H. 1985. Birth sex ratios and the reproductive success of sons and daughters. Pages 221-225 in P. J. Greenwood, P. H. Harvey, and M. Slatkin, eds. Evolution: essays in honour of John Maynard Smith. Cambridge University Press, New York.

Clutton-Brock, T. H., and S. D. Albon. 1982. Parental investment in male and female offspring in mammals. Pages 223-247 in King's College Sociobiology Group, ed. Current problems in sociobiology. Cambridge University Press, New York.

Clutton-Brock, T. H., S. D. Albon, and F. E. Guinness. 1981. Parental investment in male and female offspring in polygynous mammals. Nature (Lond.) 289:487-489.

1984. Maternal dominance, breeding success and birth sex ratios in red deer. Nature (Lond.) 308:358-360.

Cockburn, A., M. P. Scott, and C. R. Dickman. 1985. Sex ratio and intrasexual kin competition in mammals. Oecologia (Berl.) 66:427-429.

Downhower, J. F., and K. B. Armitage. 1971. The yellow-bellied marmot and the evolution of polygamy. Am. Nat. 105:355-370.

Emlen, S. T., J. M. Emlen, and S. A. Levin. 1986. Sex-ratio selection in species with helpers-at-thenest. Am. Nat. 127:1-8.

Fisher, R. A. 1930. The genetical theory of natural selection. Oxford University Press, Oxford.

Goldenberg, D. L. 1979. The effect of maternal condition on sex ratio of offspring of grey-tailed voles. Master's thesis. Oregon State University, Corvallis.

Hesseiton, W. T., and R. M. Hesselton. 1982. White-tailed deer. Pages 878-901 in J. A. Chapman and G. A. Feldhamer, eds. Wild mammals of North America. Johns Hopkins University Press, Baltimore, Md.

Knapton, R. W. 1984. Parental investment: the problem of currency. Can. J. Zool. 62:2673-2674.

Mackie, R. J., K. L. Hamlin, and D. F. Pac. 1982. Mule deer. Pages 862-877 in J. A. Chapman and G. A. Feldhamer, eds. Wild mammals of North America. Johns Hopkins University Press, Baltimore, Md.

Maynard Smith, J. 1984. The ecology of sex. Pages 201-221 in J. R. Krebs and N. B. Davies, eds. Behavioural ecology: an evolutionary approach. 2d ed. Blackwell, Oxford.

McClure, P. A. 1981. Sex-biased litter reduction in food-restricted wood rats (Neotoma floridana). Science (Wash., D.C.) 211:1058-1060.

McGinley, M. A. 1984. The adaptive value of male-biased sex ratios among stressed animals. Am. Nat. 124:597-599.

Meikle, D. B., B. L. Tilford, and S. H. Vessey. 1984. Dominance rank, secondary sex ratio, and reproduction of offspring in polygynous primates. Am. Nat. 124:173-188.

Millar, J. S. 1978. Energetics of reproduction in Peromyscus leucopus: the cost of lactation. Ecology 59:1055-1061.

1979. Energetics of lactation in Peromyscus maniculatus. Can. J. Zool. 57:1015-1019.

Myers, J. H. 1978. Sex ratio adjustment under food stress: maximization of quality or numbers of offspring. Am. Nat. 112:381-388. 